\title{
Using Organisational Culture to Enhance Knowledge Sharing in Virtual Communities
}

\author{
Imran Khan ${ }^{1}$, Abel Usoro ${ }^{2,}$, Malcolm Crowe ${ }^{3}$ \\ ${ }^{1}$ Department of Informatics, University of Sussex, Sussex, United Kingdom \\ ${ }^{2}$ Department of Mathematics and Computer Science, Ritman University, Ikot Ekpene, Nigeria \\ ${ }^{3}$ School of Computing, Engineering and Physical Sciences, Paisley, Scotland
}

Email address:

imran.khan@sussex.ac.uk (I. Khan), abel.usoro@uws.ac.uk (A. Usoro), malcolm.crowe@uws.ac.uk (M. Crowe)

${ }^{*}$ Corresponding author

\section{To cite this article:}

Imran Khan, Abel Usoro, Malcolm Crowe. Using Organisational Culture to Enhance Knowledge Sharing in Virtual Communities. American Journal of Engineering and Technology Management. Vol. 5, No. 1, 2020, pp. 1-11. doi: 10.11648/j.ajetm.20200501.11

Received: April 17, 2019; Accepted: July 3, 2019; Published: January 31, 2020

\begin{abstract}
Many knowledge sharing models have been developed but they mostly explain how knowledge flows from source to destination and hardly provide adequately validated organisational cultural factors that affect knowledge sharing in virtual communities (VCs) though VCs are recognised in literature as a software tool for knowledge sharing in organisations. The research reported in this paper undertook this task by developing a conceptual model to hypothesise the relationship between organisational culture (support, innovation, co-ordination and rules orientations) and knowledge sharing. Data was collected from over $200 \mathrm{VC}$ members. Detailed group analyses were performed to test the conceptual model. The research found that support, co-ordination and rules orientation have positive causal relationships with sharing knowledge online. The research also highlights that just a software tool like a VC will not be sufficient to enable knowledge sharing online. The implication is that training, support in personal and work problems, inter-departmental co-ordination and teamwork will have positive affect on knowledge sharing in VCs. Also, face-to-face gatherings and a leading role of managers to share their knowledge will increase online knowledge sharing. The research has implications for KM (Knowledge Management) practitioners, managers, and information systems researchers. The findings of the research can be used in assessing VC knowledge sharing systems plans from an organisational cultural perspective.
\end{abstract}

Keywords: Knowledge Sharing, Organisational Culture, Virtual Communities, Knowledge Management, Co-ordination and Rules Orientation

\section{Introduction}

A real challenge for organisations at the beginning of the millennium was "how to harness the intelligence and spirit of people at all levels of organisation to continually build and share knowledge" [1]. More recently, studies have shown that knowledge sharing provides businesses with a competitive advantage [2]; enhances innovative and performance; and reduces redundant learning efforts [3]. Many knowledge sharing models have been developed, for example, the Socialisation Externalisation Combination and Internalisation (SECI) model [4]; the model of best practice [5] and Jacobson's [7] knowledge sharing model. These models are useful in explaining how knowledge flows from source to destination, but provide little information on the factors that affect knowledge sharing. Lin [8] defines the factors that influence knowledge sharing as being information technology, individual factors, and organisational factors or culture.

Culture can be defined in many ways, but researchers tend to place more emphasis on cross cultural knowledge sharing; where knowledge is shared between participants from different cultures. For example, Li [9] investigated national cultural influences on knowledge sharing in VCs amongst Chinese and American participants. Ardichili et al. [10] researched cultural influences on knowledge sharing in China, Brazil and Russia. Shahnaz, Usoro and Khan [10, 11] highlighted the considerations of societal culture on 
knowledge sharing and investigated it empirically. However, Ardichili et al. [10] highlighted the need to investigate the relationship of organisational culture with knowledge sharing in VCs (p. 104); an area which has been largely ignored by the research community. The rest of this paper will present the research hypotheses; empirical work design; demographic characteristics; further data analyses; findings; validated research model; and conclusions, limitations and future work.

\section{Research Hypotheses}

The research will utilise the organisational cultural model developed by Khan et al. [13]. The model consists of support, innovation, co-ordination and rules orientations. The model has been tested in different organisations and has a strong base in literature.

The research generated the following hypotheses to examine the relationship between organisational cultural and knowledge sharing in VCs.

$\mathrm{H}_{1}$ : A VC member employed by a highly supportive oriented organization may share more knowledge in a VC.

$\mathrm{H}_{2}$ : A VC member employed by a highly innovative organization may share more knowledge in a VC.
$\mathrm{H}_{3}$ : A VC member employed by a highly coordinated oriented organization may share more knowledge in a VC.

$\mathrm{H}_{4}$ : A VC member employed by a highly rules-oriented organization may share more knowledge in a VC.

$\mathrm{H}_{5}$ : A VC member employed by a less supportive oriented organization may share less knowledge in a VC.

$\mathrm{H}_{6}$ : A VC member employed by a less innovative oriented organization may share less knowledge in a VC.

$\mathrm{H}_{7}$ : A VC member employed by a less rules-oriented organization may share more knowledge in a VC.

$\mathrm{H}_{8}$ : A VC member employed by a less rules-oriented organization may share more knowledge in a VC.

The hypotheses and associated variables were combined to develop a research model, which is shown in Figure 1 below. The long horizontal arrow represents the level of organisational culture; with the two extremes of the arrow representing high and low oriented organisational cultures. A high oriented organisational culture exists where organisations place emphasis on support, innovation, co-ordination and rules. A low oriented organisational culture exists where organisations place little or no emphasis on support, innovation, coordination, and rules. Between these two extremes, organisational culture decreases from left to right. Knowledge sharing activity is represented by the cloud shape.

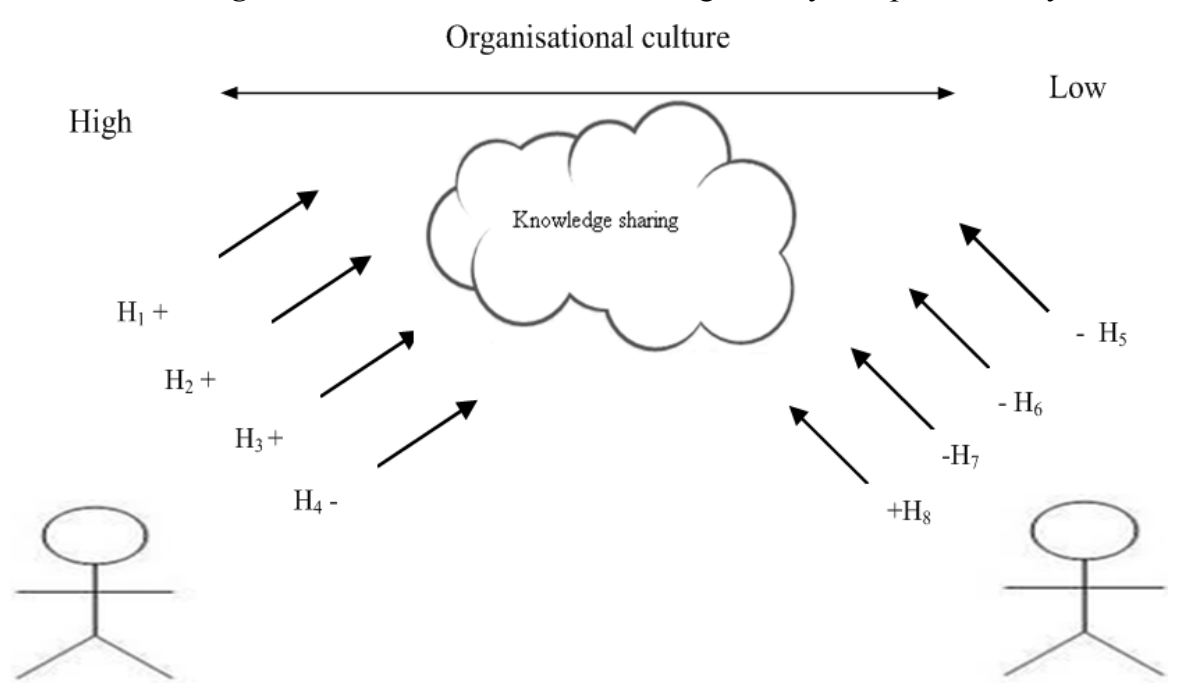

Figure 1. Research model.

\section{Empirical Work Design}

\subsection{Pilot Testing}

The questionnaire was designed which has four sections: (1) Demographic (2) organisational culture (3) knowledge sharing and (4) open end questions. For organisational culture, questionnaire items developed by Khan et al. [13] are used. The knowledge sharing questionnaire items are adopted from the work of Usoro et al. [14] and Lin [8].

Pilot testing was carried out in two stages. In the first stage, it was shown to five expert researchers and eight research students in the University of the West of Scotland. As a result, many changes were made to the questionnaire, mainly in relation to language, grammar and structure. For example, one expert highlighted that the following changes should be made to questions as the wording of the questions was unclear:

"I would say that with respect to Section B, question 4 and perhaps even 5, 6 and 7 are difficult to measure without taking into account feedback from other peers. ---."

The second stage involved posting a link of the questionnaire in the Gurteen Knowledge Management Community. Members of the community were invited to complete the survey and provide comments. A total of 32 responses were received, 21 of which were valid. The data were analysed and did not reveal any statistical issues.

Some comments indicated that respondents thought that the research was addressing important questions:

"This is very good questionnaire and well developed 
questions. One of the topics I teach is 'The effects of internal culture on companies that want to expand their business internationally'. Therefore, I would appreciate if you would agree to come and talk to my students for 10-15 minutes to explain how important this factor is."

"Imran, the Henley Knowledge Forum just finished a project on using Web 2.0 (social networks) in the business community, during which they interviewed students coming into the business world. Might be interesting reading for your research; contact

http://www.henley.reading.ac.uk/executiveeducation/excellen ce/cl-knowledgemanagementforum.aspx"

\subsection{Sample Selection (Virtual Community Selection)}

A sample is a group that is selected from a population [15]. Time and cost constraints require that a sample be selected for the study, as it is neither realistic nor possible to study every Virtual Community (VC) in existence [16]. However, it is important to ensure that the sample is representative of the population under investigation.

The population for this research includes all active $\mathrm{VC}$ members employed by organisations, whether the $\mathrm{VC}$ was started by an organisation or by members of the VC. Many such communities exist, and a list of these communities makes up the sampling frame for the research. The researcher joined and studied a range of Virtual Communities (VCs) for example, LIKE (The London Information and Knowledge Exchange); NetIKX (Network of Information and Knowledge Exchange); the Knowledge Network (NHS, Scotland); and the Gurteen Knowledge Community. Although all these VCs were considered as a sample, LIKE was selected in order to deal with survey research issues like coverage and non-response [15].

LIKE (the London Information and Knowledge Exchange) is a community of information and knowledge professionals. They hold monthly face to face meetings in London, to share stories, learn, and exchange knowledge in an informal environment, usually a pub. The environment is very friendly, interesting and engaging and the discussion is rich, informative, and socially enjoyable. In addition to face to face discussions, the community members discuss topics on LinkedIn and Twitter, and knowledge is shared by writing blogs. LIKE attracts a global membership, with members based in India, Saudi Arabia, Australia, New Zealand, Canada, USA, Spain, Hong Kong, South Africa and the UK. The virtual community can be accessed at http://www.likenews.org.uk.

\section{Demographic Characteristics}

\subsection{Age}

Figure 2 shows that the mean age of respondents was 43 with a standard deviation of 10 years. The majority of respondents were between 25 and 58, representing a working age group. Very few respondents were over 60 and the majority of respondents who are working were around age 50. This is a very good age range for such a study, as younger respondents may have had less work experience.

\subsection{Gender}

From valid responses $37.1 \%$ were male and $47.5 \%$ were female. As such, more females than males had completed the questionnaire.

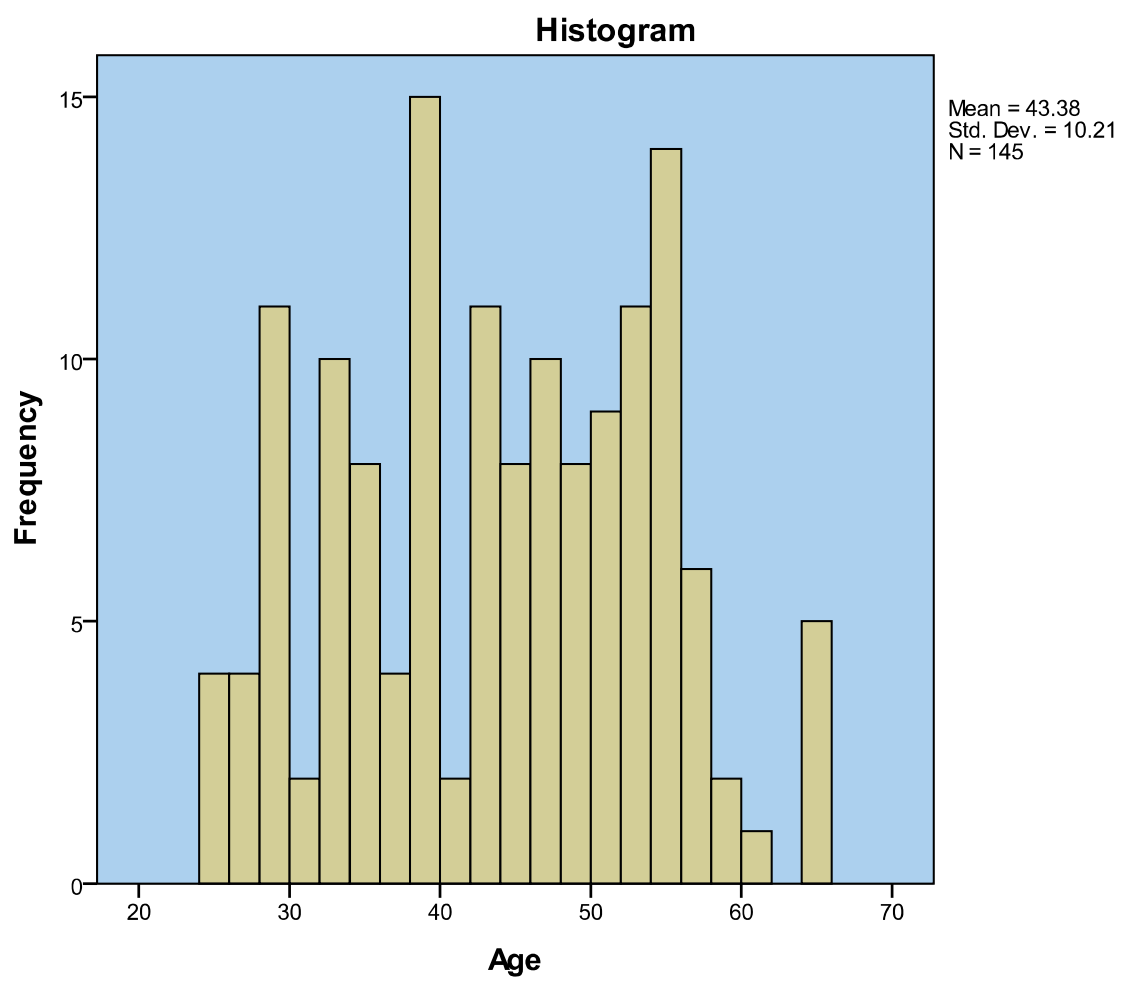

Figure 2. Age of respondents. 
Table 1. Percentage of Male and Female Respondents.

\begin{tabular}{lllll}
\hline & & Frequency & Percent & Valid Percent \\
\hline \multirow{3}{*}{ Valid } & Male $=1$ & 75 & 37.1 & 43.9 \\
& Female=2 & 96 & 47.5 & 56.1 \\
System missing & Total & 171 & 84.7 & 100.0 \\
Total & 31 & 15.3 & \\
\hline
\end{tabular}

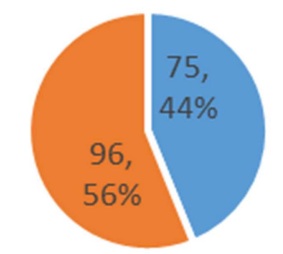

\section{- Male - Female}

Figure 3. Gender of respondents.

\subsection{Experience}

Figure 4 below indicates that the majority of respondents have less than 5 years' work experience. A number of respondents have more than 10 years and a few have over 20 years.

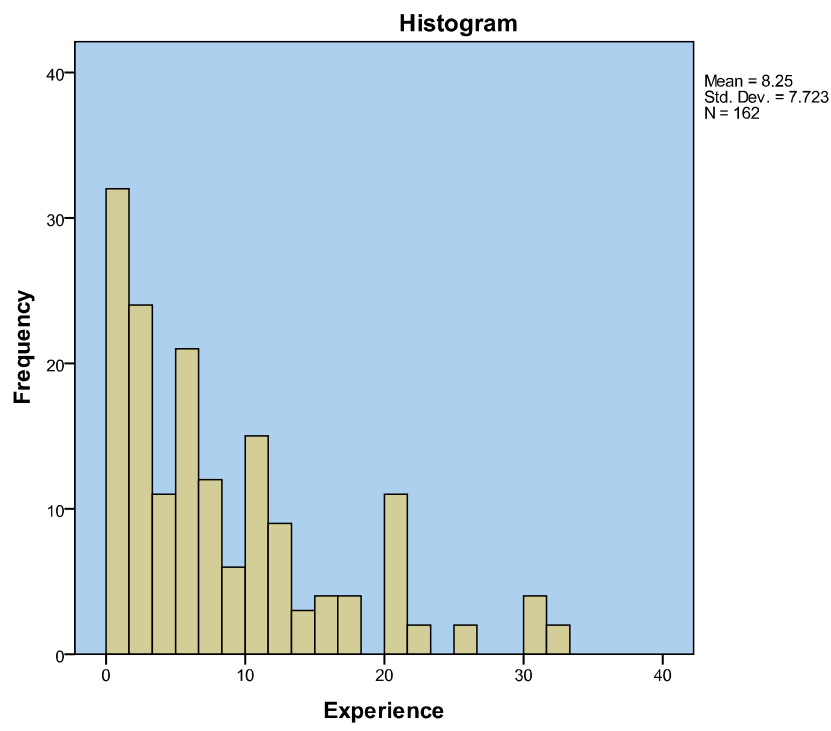

Figure 4. Experience of respondents.

\subsection{Education}

Table 2 shows the highest level of educational qualification attained by respondents. Just over $45 \%$ of respondents were educated to Master's degree level and above; $23.6 \%$ having a Bachelor's degree; $2 \%$ holding an $\mathrm{HND}$ or $\mathrm{HNC}$; and $3 \%$ having only higher and standard grades. Overall, the respondents had a high level of educational qualification, which may have a positive effect on the quality of data as they will understand the value of the research, and provide high quality data.

Table 2. Education of respondents.

\begin{tabular}{llll}
\hline & & Frequency & Percent \\
\hline \multirow{6}{*}{ Valid } & PhD $=1$ & 2 & 1.0 \\
& Master $=2$ & 90 & 44.3 \\
& PG Diploma or Certificate $=3$ & 24 & 11.8 \\
& BA, BSc $=4$ & 48 & 23.6 \\
& HNC, HND $=5$ & 4 & 2.0 \\
& Higher and Standard Grades $=5$ & 6 & 3.0 \\
Missing & Total & 174 & 85.7 \\
Total & System & 29 & 14.3 \\
\hline
\end{tabular}

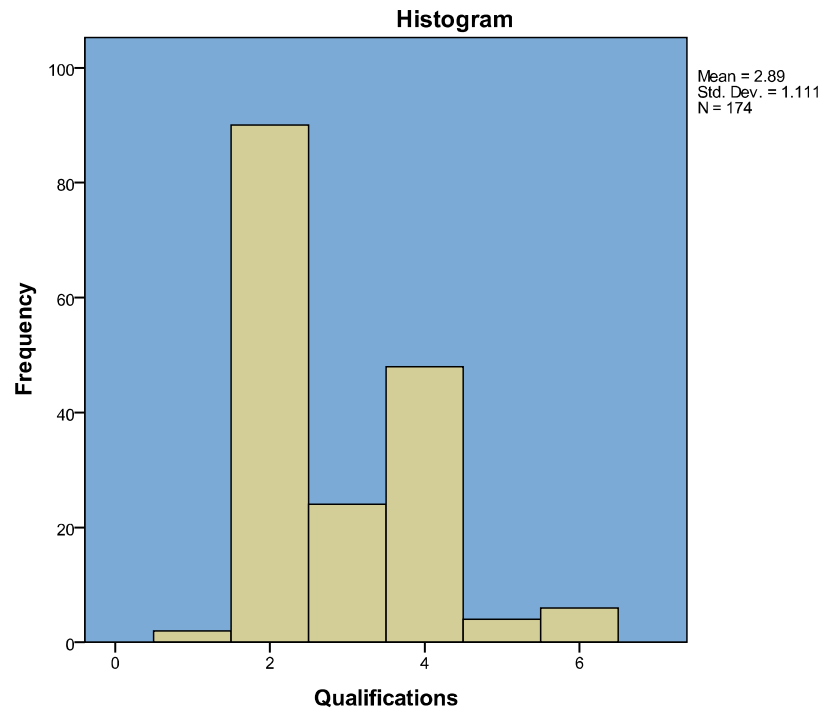

Figure 5. Respondents highest level of educational qualification.

\section{Further Data Analysis}

\subsection{Parametric Versus Non-parametric Data}

This section endeavours to examine relationships between organisational culture and knowledge sharing. If data do not meet parametric assumptions, then non-parametric tests should be used. According to Field [17] and Pallant [18], if the Kolmogorov-Smirnov test is significant then normality assumption is violated. Violation of normality can also be checked from Skewness and Kurtosis. Skewness provides an indication of the symmetry of distribution and kurtosis provides information on the 'peakedness' of the distribution of data. In a perfect normal distribution, kurtosis and skewness will equal zero.

Table 3 shows that the Kolmogorov-Smirnov test is significant, and as such the normality assumption is violated. Skewness is -.172, which means a high number of respondents selected agree and strongly agree. Kurtosis is also negative and equal to -.305 . It means that more cases are in the extremes. These skewness and kurtosis values indicate that the normality assumption has been violated. 
Table 3. Tests for Normality

\begin{tabular}{lllllll}
\hline & \multicolumn{2}{l}{ Kolmogorov-Smirnov } & \multicolumn{3}{l}{ Shapiro-Wilk } \\
\cline { 2 - 8 } & Statistic & df & Sig. & Statistic & df & Sig. \\
\hline Knowledge Sharing & .164 & 101 & .000 & .970 & 101 & .023 \\
\hline
\end{tabular}

To confirm if data meet linearity, Field [17] and Pallant [18] suggest examining Normal Q-Q plot. A straight line indicates that data is linear. Figure 6 below shows a straight line. Therefore, this assumption has been met.

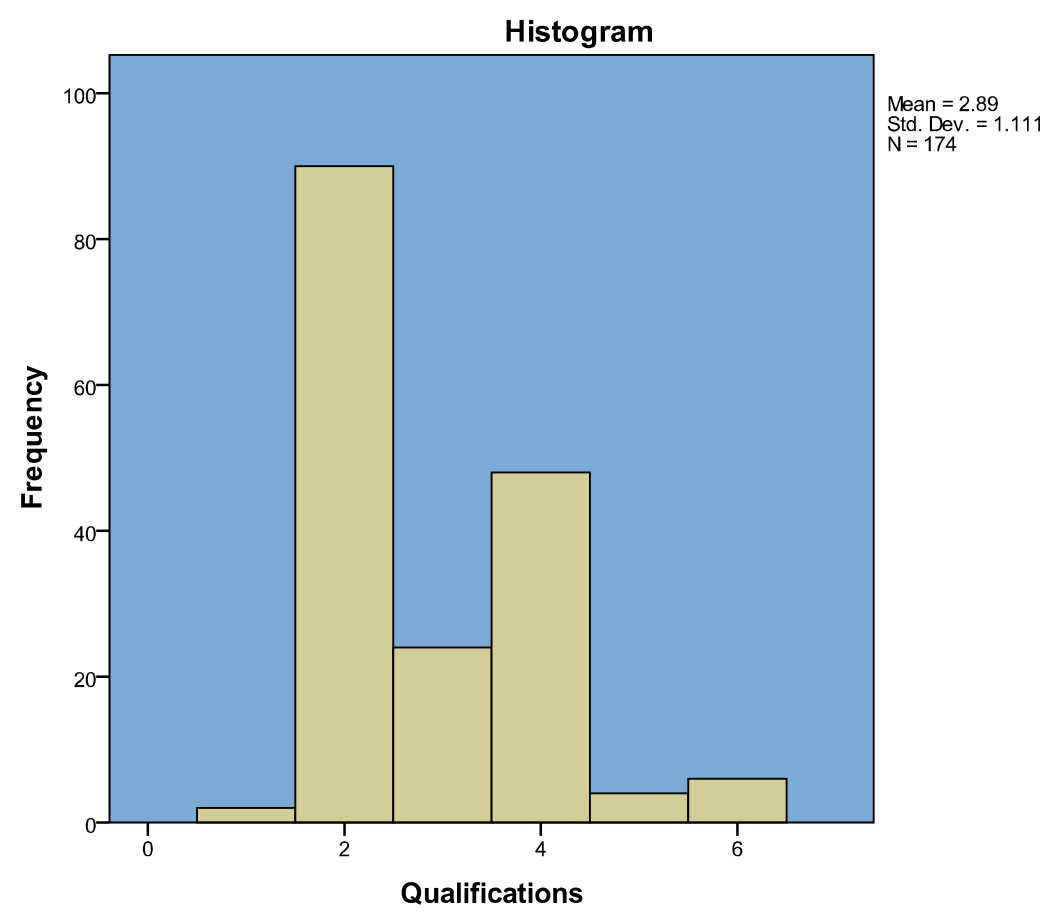

Figure 6. Normal $Q-Q$ plot of knowledge sharing.

Homoscedasticity can be checked by inspecting scores. A 'cigar' shape of data distribution indicates that this assumption has been met $[17,22]$. Inspecting the scatter plot of knowledge sharing and organisational cultural factors in the figure 7 below indicate that homoscedasticity assumption

\section{has been violated.}

Of the three main assumptions required to be met for parametric tests to be conducted, only linearly has been satisfied. Therefore, a non-parametric test will be used.

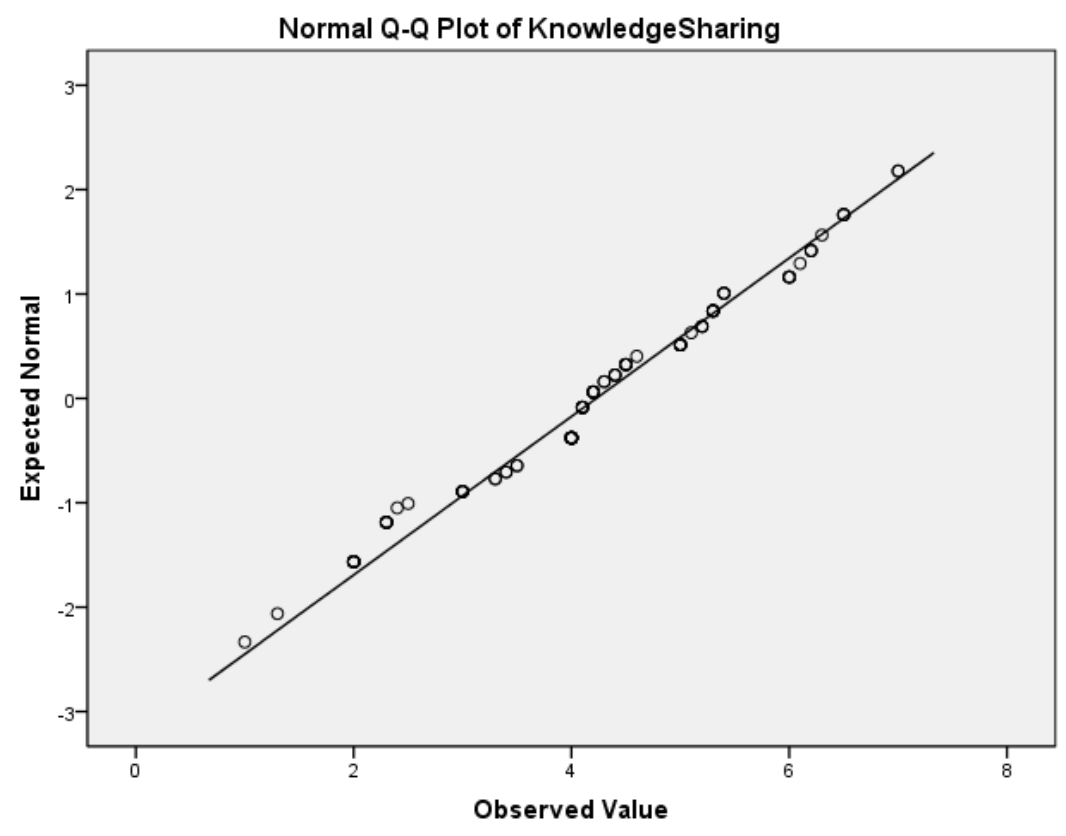

Figure 7. Scatter plot. 
A non-parametric correlation test, Spearman's rho, is selected to test the relationships between knowledge sharing and organisational cultural factors. Cohen, Mansion and Morrison [19] suggest the following guidelines for checking the output of Spearman's rho against the values listed below:

Small $\mathrm{r}=.10$ to .29

Medium $r=.30$ to .49

Large $\mathrm{r}-.5$ to .1

Table 4. Spearman's rho Correlation analysis.

\begin{tabular}{llllll}
\hline Correlations & & & & & \\
\hline & & Support Orientation & Innovation Orientation & Coordination Orientation & Rules Orientation \\
\hline \multirow{2}{*}{ Knowledge } & Spearman's Correlation & $.242^{* *}$ & -.086 & -.002 & $.186^{*}$ \\
Sharing & Sig. (2-tailed) & .001 & .260 & .982 & .015 \\
& $\mathrm{~N}$ & 174 & 174 & 174 & 172 \\
\hline
\end{tabular}

**. Correlation is significant at the 0.01 level (2-tailed).

*. Correlation is significant at the 0.05 level (2-tailed).

The correlation analysis (see table 4) did not show a satisfactory result. Therefore, further analysis will be carried out on the data.

\subsection{Grouping (Clustering) of Data}

In order to provide a more detailed analysis, the data will be classified into different subgroups, which will then be analysed based on the variations between dependent and independent variables. In order to classify data into homogenous cases as subgroups, an exploratory data analysis tool known as cluster analysis is commonly used. However, this research will not use cluster analysis as the levels on independent variables (strongly disagree to strongly agree) can be considered as being different groups. For example, respondents who strongly agree on support orientation can be considered as one group while respondents in other categories such as agree and disagree form other groups. Such an approach to forming groups have been used successfully by researchers such as Al-alawi et al. [20], and is referred to as the 'planned groups' tool by Pallant [18].

Each of the organisational cultural factors is measured using a 7-point Likert scale from 1 to 7; where 1 represents strongly disagree, 2 disagree, 3 slightly disagree, 4 neutral, 5 slightly agree, 6 agree and 7 is equal to strongly agree. On the basis of this scale, a total of seven groups can be formed, making group analysis and interpretation a complex and difficult task. Therefore, values on the scale will be merged to form new groupings; the slightly disagree and disagree values will be merged; and the slightly agree will be merged with agree. Neutral (4) will not be considered in these grouping, but will be examined for patterns. For example, if a large number of respondents have selected neutral on a particular option, it will be reported only if there is a significant result. Following this approach, a total of four groups can be formed as listed below in table 5:

Table 5. Groups.

\begin{tabular}{ll}
\hline $\begin{array}{l}\text { Levels of Organisational Cultural Factors (in descending } \\
\text { order) }\end{array}$ & Group \\
\hline Strongly agree & 1 \\
Agree & 2 \\
Disagree & 3 \\
Strongly disagree & 4 \\
\hline
\end{tabular}

The mean value of the dependent variable (knowledge sharing) will be examined against the different groups. If the mean of the dependent variable increases or decreases with the increase or decrease in the groups of an independent variable, then there is a positive relationship between the variables [20]. For example, if the mean value of knowledge sharing is 0.5 in the disagree group of support orientation, increasing to 1.5 in the agree group, and increases further in the strongly agree group then it can be said that knowledge sharing has a positive relationship with support orientation in VCs.

To perform group analysis between more than one group, a non-parametric Kruskal-Wallis test is performed [17, 22].

\subsection{Hypothesis Testing}

\subsubsection{Support Orientation and Knowledge Sharing}

A Kruskal-Wallis test was performed which generated the output given in table 6 . It revealed a significant difference in knowledge sharing across the four different support orientation levels; as indicated by the increase in the mean of knowledge sharing with an increase in the level of support orientation.

The observed Chi-square value in the table 6 is 20.601 and the $\mathrm{df}$ is 2 . The critical value for $\mathrm{df}=2$ at $\mathrm{p}=.05$ is 5.99 . If the observed value is bigger than the critical value, it means there is a significant relationship between the two variables [17]. Thus, knowledge sharing and support orientation have a significant relationship at $\mathrm{p}=.05$.

Table 6 shows that the mean rank of knowledge sharing increases with an increase in the level of support orientation. In the disagree group, the mean of the knowledge sharing is 58.85 , increasing to 66.06 in the agree group, and 115.64 in the strongly agree group. Therefore, the results show that knowledge sharing in VCs increases with an increase in the level of support orientation. The output of the test confirms the two hypotheses related to support orientation. An employee of highly supportive organisation will share more knowledge in a $\mathrm{VC}$ than an employee from a less supportive organisation.

Table 6. Levels of support orientation versus mean of knowledge sharing.

\begin{tabular}{ll}
\hline Levels of support orientation & Mean rank of knowledge sharing \\
\hline Disagree & 58.85 \\
Agree & 66.06 \\
Strongly agree & 115.64 \\
\hline
\end{tabular}

Chi-square $=20.601 ; \mathrm{df}=2$; and $\mathrm{p}=.000$. 


\subsubsection{Innovation Orientation and Knowledge Sharing}

A Kruskal-Wallis test was carried out to test innovation orientation relationship with knowledge sharing in VCs. The output generated is shown in table 7 . The observed Chi-square value (4.07) is less than the critical value (7.81) at $\mathrm{df}=3$ and $\mathrm{p}=.05$. The observed value is less than the critical value which means there is an insignificant relationship between knowledge sharing and innovation orientation in Virtual Communities (VCs).

The change in the mean value of knowledge sharing shows no clear patterns of change with the increase in innovation orientation. It shows an increase from 50.00 to 75.50 with a change in innovation orientation from 'strongly disagree' to 'disagree'. However, the mean value of knowledge sharing decreases from 75.50 to 60.07 when innovation orientation change from 'disagree' to 'agree' group. It decreases further to 52.29 for the 'strongly agree' group. With the exception of the increase from the strongly disagree to agree group, the mean value of knowledge sharing in VCs decreases with the increase in innovation orientation. Thus, the data does not confirm the hypotheses $\mathrm{H}_{2}$ and $\mathrm{H}_{6}$. However, further analysis will be performed to examine relationships between the components of innovation orientation and knowledge sharing.

Table 7. Levels of innovation orientation versus mean rank of knowledge sharing.

\begin{tabular}{ll}
\hline Levels of innovation orientation & Mean rank of knowledge sharing \\
\hline Strongly disagree & 50.00 \\
Disagree & 75.50 \\
Agree & 60.07 \\
Strongly agree & 52.29 \\
\hline
\end{tabular}

Chi-square $=4.0 ; \mathrm{df}=3$; and $\mathrm{p}=.254$.
Innovation orientation consists of the constructs of openness to criticism, sharing knowledge, sharing information freely, encouragement of ideas by management, and risk taking. To analyse if the 'sharing knowledge' construct causes the insignificant result between innovation orientation and knowledge sharing, it was removed from the innovation orientation variable. Tables 8 and 9 show the test results for the relationship between innovation and knowledge sharing when the 'sharing knowledge' construct is removed from the innovation orientation data. The Kruskal-Wallis test provides an insignificant result, showing that the removal of the sharing knowledge data does not affect the outcome.

Table 8. Innovation orientation without sharing of knowledge constructs.

Test statistics

Chi-square $=2.00 ; \mathrm{df}=3$ and $\mathrm{p}=0.572$

The table 9 shows the variations in the mean of knowledge sharing against the component parts of innovation orientation. The mean fluctuates in all components of innovation orientation, with the exception of risk taking where it shows an increase from 58.93 to 62.73 between the 'disagree' and 'agree' groups, and to 84.63 in the 'strongly agree' group. This means that with the exception of risk taking, the other components have no relationship with knowledge sharing. An increase in the level of risk taking shows knowledge sharing will increase, thus it can be said that there is a positive relationship between risk taking and knowledge sharing in VCs.

Table 9. Levels of innovation orientation versus mean of knowledge sharing.

\begin{tabular}{llll}
\hline Levels & openness to criticism & information easily shared & management encouraging new ideas \\
\hline Strongly disagree & 96.00 & 45.75 & 65.38 \\
Disagree & 75.69 & 85.08 & 85.46 \\
Agree & 64.85 & 74.59 & 69.55 \\
Strongly agree & 60.41 & 74.75 & 67.52 \\
\hline
\end{tabular}

\subsubsection{Co-ordination Orientation and Knowledge Sharing}

Relationship between co-ordination and knowledge sharing were tested using Kruskal-Wallis test which generated the output listed in table 10. The observed Chisquare value 5.497 is slightly lower than the critical value 5.99 at $\mathrm{df}=2$ and $\mathrm{p}=.05$. This indicates a significant positive relationship between co-ordination orientation and knowledge sharing. Knowledge sharing will increase or decreases if the levels of co-ordination increase or decrease.

The mean of knowledge sharing decreases from 71.38 to 65.02 with an increase in the level of coordination level from 'disagree' to 'agree', and a large increase to 89.19 at strongly agree. On that basis it can be deduced that the mean value of knowledge sharing increases with the increase in coordination orientation. Thus, an individual working in a highly co-ordination oriented culture will share more knowledge in a VC compared to an individual working in a less coordinated organization. This confirms $\mathrm{H}_{3}$ and $\mathrm{H}_{7}$ but the slight decrease in the mean at 'disagree' to 'agree' level gives cause for concern. Further analysis is required to investigate further.

Table 10. Levels of co-ordination versus knowledge sharing mean.

\begin{tabular}{ll}
\hline Levels of co-ordination orientation & Mean rank of knowledge sharing \\
\hline Disagree & 71.38 \\
Agree & 65.02 \\
Strongly agree & 89.19 \\
\hline
\end{tabular}

Chi-square $=5.497 ; \mathrm{df}=2$; and $\mathrm{p}=.064$.

Co-ordination orientation consists of components of interdepartmental co-ordination, teamwork and organisation structure. Table 10 shows how knowledge sharing's mean varies for each group in relation to these components.

The inter-departmental component, the mean of knowledge sharing is 87.67 in the 'strongly disagree' group, falling to 79.08 in the disagree group. The mean value shows a sharp increase from 61.23 to 92.86 from the 'agree' to 
'strongly agree' group. Overall, the mean value of knowledge sharing increases from the 'strongly disagree' to 'strongly agree' group, and as such, knowledge sharing is shown to have a significant positive relationship with interdepartmental coordination.

The mean value for knowledge sharing was 78.02 in the 'disagree' group, falling slightly to 73.04 in the 'Agree' group. In the higher group 'strongly agree', the mean value of knowledge sharing was 100.07, showing a large from the 'agree' group. Overall incline of knowledge sharing's mean is that it increases from a lower level group to a higher level group. Thus, it can be said that teamwork has a significant positive relationship with knowledge sharing.

\subsubsection{Rules Orientation and Knowledge Sharing}

The relationships between rules orientation and knowledge were tested using a Kruskal-Wallis which generated the output shown in table 11. The output shows a significant relationship between rules orientation and knowledge sharing. The observed Chi-square value of 15.473 is higher than the critical value 5.99 at $\mathrm{df}=2$ and $\mathrm{p}=.05$; indicating a significant relationship between rules orientation and knowledge sharing in VCs.

The mean value of knowledge sharing increases from 56.32 in the 'disagree' group to 56.80 in the 'agree' group, and shows a large increase to 96.42 in the 'strongly agree' group. Thus, the mean of knowledge sharing increases from disagree, to agree and to strongly agree. Therefore, $\mathrm{H}_{4}$ and $\mathrm{H}_{8}$ are rejected.

Table 11. Levels of rules orientation versus the mean of knowledge sharing.

\begin{tabular}{ll}
\hline Levels of rules orientation & Mean rank of knowledge sharing \\
\hline Disagree & 56.32 \\
Agree & 56.80 \\
Strongly agree & 96.42 \\
\hline
\end{tabular}

Chi-square $=15.473 ; \mathrm{df}=2$; and $\mathrm{p}=.000$.

\subsection{Significant Organisational Culture Factors}

Table 12 summaries the results in relation to the research hypotheses. The support orientation hypotheses, $\mathrm{H}_{1}$ and $\mathrm{H}_{5}$, are accepted as support orientation was found to have a significant positive relationship with knowledge sharing in VCs.

Co-ordination orientation hypotheses, $\mathrm{H}_{3}$ and $\mathrm{H}_{7}$, are accepted as co-ordination orientation was found to have a significant positive relationship with knowledge sharing in VCs.

It was assumed that rules orientation has a negative relationship with knowledge sharing. However, a positive relationship was found to exist. Rules orientation hypotheses, $\mathrm{H}_{4}$ and $\mathrm{H}_{8}$, were rejected.

A positive relationship was assumed between innovation and knowledge sharing, represented by $\mathrm{H}_{2}$ and $\mathrm{H}_{6}$. However, the data shows no clear picture of any relationship between the two. Therefore, further research is required.

Table 12. List of hypotheses accepted and rejected.

\begin{tabular}{llll}
\hline Organisational culture factor & Hypotheses & Outcome & Relationship \\
\hline \multirow{2}{*}{ Support orientation } & $\mathrm{H}_{1}$ & Accepted & Positive \\
& $\mathrm{H}_{5}$ & Accepted & Positive \\
Co-ordination orientation & $\mathrm{H}_{3}$ & Accepted & Positive \\
& $\mathrm{H}_{7}$ & Accepted & Positive \\
Rules orientation & $\mathrm{H}_{4}$ & Rejected & Positive \\
& $\mathrm{H}_{8}$ & Ro rected & Positive \\
Innovation orientation & $\mathrm{H}_{2}$ & No relationship & No relationship \\
& $\mathrm{H}_{6}$ & & No relationship \\
\hline
\end{tabular}

\section{Findings}

The findings in this section relate to relationships between organisational culture and knowledge sharing in VCs.

\subsection{Support Orientation and Knowledge Sharing in Virtual Communities}

Relationships between support orientation and knowledge sharing in VCs were hypothesized as follows:

$H_{1}$ : A member of a highly supportive organization may share more knowledge in VCs.

$H_{5}$ : A member of a less supportive organization may share less knowledge in VCs.

A significant result was found for the relationship between support orientation and the level of knowledge sharing. $\mathrm{H}_{1}$ and $\mathrm{H}_{5}$ were accepted, meaning that an individual who has more support from his or her organisation will share more knowledge in VCs. If support increases, the level of knowledge sharing in VCs will also increase. If support decreases, the level of knowledge sharing in VCs will decrease.

\subsection{Innovation Orientation and Knowledge Sharing in Virtual Communities}

Relationships between innovative orientation and knowledge sharing in VCs were hypothesized as follows:

$\mathrm{H}_{2}$ : A member of a highly innovative organization will share more knowledge in VCs.

$\mathrm{H}_{6}$ : A member of a less innovative organization will share less knowledge in VCs.

However, analysis of data supported the rejection of $\mathrm{H}_{2}$ and $\mathrm{H}_{6}$, meaning that innovation orientation does not have a significant relationship with the level of knowledge sharing in VCs. This finding is not in line with previous studies in real life communities, which show a strong relationship between innovation and knowledge sharing. For instance, Roger et al. (2002) [3], Scarbgrough (2003) [21] and 
Kamasak and Bulutlar (2010) [22], all found that knowledge sharing is a key factor in innovation. Dougherty et al. [23] found that innovation relies on accumulation of new knowledge sharing, and that VCs are considered as sociotechnical systems [24, 25] which provides a platform to socialise, share and accumulate new knowledge [26, 8].

Rejection of hypotheses can relate to a finding of research, or mistakes in research design. There are many types of mistakes that can lead to the rejection of a hypothesis. Examples of such mistakes include constructs being invalid or unreliable, or a questionnaire being unclear. One of three reasons might have caused the rejection of $\mathrm{H}_{2}$ and $\mathrm{H}_{6}$ :

a) There may have been problems with the reliability and validity of the constructs of innovation orientation.

b) The chosen sample, LIKE, is not a representative sample.

c) The rejection may indicate a finding from the research.

The constructs of innovation orientation have a strong base in the literature. They were tested on different types of organisations and their validity and reliability were acceptable. Therefore, it can be said with confidence that the constructs have not caused the rejection of $\mathrm{H}_{2}$ and $\mathrm{H}_{6}$.

The research considers a VC whose members are from different organisations. LIKE's members work in both public and private sector organisations. Pilot testing of the questionnaire was performed in another $\mathrm{VC}$ with no problems identified. Selecting a representative $\mathrm{VC}$ is a difficult task as there are various types of $\mathrm{VCs}$, and differentiation between types is difficult. LIKE was chosen as it meets the requirement specified by the research for a $\mathrm{VC}$ which is that members of the $\mathrm{VC}$ should work in different organisations. Therefore, it can be said that the sample is a representative sample and did not cause the rejection of $\mathrm{H}_{2}$ and $\mathrm{H}_{6}$.

As such, the remaining option is that the rejection of the hypotheses could represent a real finding of the research. In Virtual Communities, unlike in real communities, there may not be a relationship between knowledge sharing and innovation. This would mean that an individual employed by a highly innovative organisation might not share more knowledge than one from a less innovative organisation. Before concluding the relationship between the two variables, the research examined the constituent constructs of innovation orientation and their relationships with knowledge sharing in VCs.

Innovation orientation consists of: openness to criticism, easy sharing of information, sharing knowledge, managers' encouragement of new ideas, and risk taking. As sharing of knowledge is also a construct of innovation orientation, it was removed from innovation orientation to investigate if it had led to the rejection of $\mathrm{H}_{2}$ and $\mathrm{H}_{6}$. However, this did not improve the results and the data did not support $\mathrm{H}_{2}$ and $\mathrm{H}_{6}$. Next, each construct of innovation orientation was checked against knowledge sharing. Only the construct of risk taking was found to have a positive relationship with the level of knowledge sharing in VCs, meaning that an employee of a high risk oriented organisation will share more knowledge in a VC.

$\mathrm{H}_{2}$ and $\mathrm{H}_{6}$ were rejected both at the factor and construct levels of data analysis. Thus, it can be said that there is no relationship between innovation orientation and knowledge sharing in VCs.

\subsection{Coordination Orientation and Knowledge Sharing in Virtual Communities}

Relationships between co-ordination orientation and knowledge sharing in VCs were hypothesized as follows:

$\mathrm{H}_{3}$ : A member of a highly coordinated organization may share more knowledge in VCs.

$\mathrm{H}_{7}: A$ member of a less coordinated organization may share less knowledge in VCs.

A significant result was found for the relationship between coordination orientation and knowledge sharing in VCs. $\mathrm{H}_{3}$ and $\mathrm{H}_{7}$ were accepted, meaning that a member from a highly coordinated organization will share more knowledge in VCs compared to another member who is from a less coordinated organization. Results show a medium positive relationship between co-ordination orientation and knowledge sharing in VCs. This suggests that an increase in co-ordination in an organization will lead to an increase in knowledge sharing in a VC. Earlier studies in real communities also support this finding. For instance, Nonaka and Takeuchi [4] highlighted that co-ordination between employees significantly affects the transfer of tacit knowledge to explicit knowledge.

The constituent constructs of co-ordination orientation defined as inter-departmental co-ordination, teamwork and organization structure were also checked against knowledge sharing in VCs. Inter-departmental coordination and teamwork were found to have more positive relationships with knowledge sharing in VCs, while results were not clear for organization structure. At the top level of coordination, teamwork contributed more than the other two components of coordination orientation. As such, teamwork was found to have a strong positive relationship with knowledge sharing in VCs.

It can be said with confidence that there is a positive relationship between co-ordination orientation and knowledge sharing in VCs.

\subsection{Rules Orientation and Knowledge Sharing in Virtual Communities}

From the literature review, relationships between rules orientation and knowledge sharing in VCs were hypothesized as follows:

$\mathrm{H}_{4}$ : A member of a highly rules oriented organization may share less knowledge in VCs.

$\mathrm{H}_{8}$ : A member of a less rules oriented organization may share more knowledge in VCs.

$\mathrm{H}_{4}$ and $\mathrm{H}_{8}$ represent a negative relationship between rules orientation and knowledge sharing in VCs. However, analysis of the data supported the rejection of $\mathrm{H}_{4}$ and $\mathrm{H}_{8}$ meaning that there could be a positive relationship between rules orientation and knowledge sharing in VCs. An 
individual from a highly rules oriented organization may share more knowledge in VCs. However, an individual from a less rules oriented organization may share less knowledge.

The data analysis also examined relationships between constructs of rules orientation and knowledge sharing in VCs. Rules orientation has three components: following procedures, managers' instructions, and standards. Following procedures and managers' instructions was found to have a positive relationship with knowledge sharing, with following managers' instructions having the strongest relationship. This is in line with existing literature on VCs and KM. Many scholars have emphasized the importance of managers for the success of a VC and KM. For instance, Hiebeler [27] found that top leadership must be committed to share organisational knowledge, as lack of sharing can often be a reason for poor KM performance. The final component of rules orientation, following standards, was found to have no relationship with knowledge sharing.

The analysis at the factor and constructs levels show a positive relationship with knowledge sharing in VCs. Thus, it can be said that there is a positive relationship between rules orientation and the level of knowledge sharing in VCs.

\section{Validated Research Model}

Support orientation, co-ordination and rules orientation have been found to have significant positive relationships with knowledge sharing in VCs, whilst innovation orientation has no significant relationship with knowledge sharing in VCs.

Validating the conceptual research model (figure 1) has resulted in making changes in two aspects. The first is about innovation orientation and knowledge sharing relationship. The conceptual model shows that innovation orientation and knowledge sharing have a relationship in VCs represented by two hypotheses $\mathrm{H}_{2}$ and $\mathrm{H}_{6}$. The data analysis shows that there is no significant relationship between these two factors. As a result, the validated research model does not show this relationship. The second is related to rules orientation and knowledge sharing relationship. The two hypotheses, $\mathrm{H}_{4}$ and $\mathrm{H}_{8}$, show relationship between rules orientation and knowledge sharing in VCs. $\mathrm{H}_{4}$ conceptualises that high rules orientation may affect knowledge sharing negatively and $\mathrm{H}_{8}$ indicates that low rules orientation may affect knowledge sharing positively in VCs. In data analysis the results did not support these hypotheses. The results showed that high rules orientation will increase knowledge sharing while low rules orientation will decrease sharing of knowledge in VCs. This positive relationship between the two variables is reflected in the valid model by an arrow with a positive sign on it. The valid research model with dimensions of organisational cultural factors is displayed in figure 8 . This is another way of representing relationship between knowledge sharing and organisational cultural factors.

Organisational culture

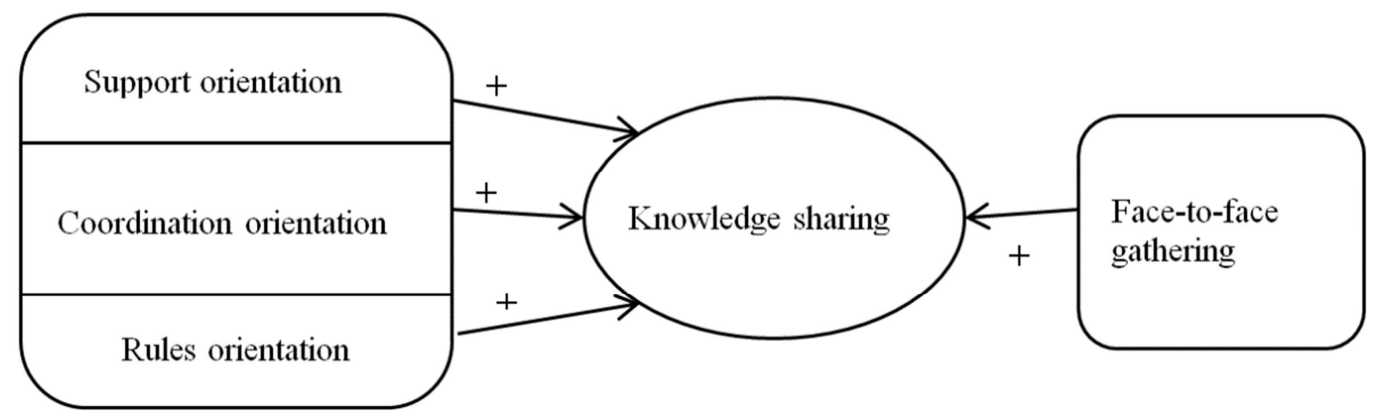

Figure 8. Validated research model.

\section{Conclusions, Limitations and Future Work}

The argument of this research are as follows:

a) Training, support in personal and work problems, interdepartment co-ordination, and teamwork will increase knowledge sharing in VCs.

b) Knowledge sharing should be made a part of organisational procedures, and managers should share their knowledge. Procedures which involve knowledge management processes should be encouraged. Managers should be encouraged to share knowledge in VCs, as staff would follow them.

c) Face-to-face gatherings should be organised to increase knowledge sharing in a VC.
Organisations should be interested in making knowledge sharing systems succeed.

The conclusion of the research is that KM managers should promote work practices specified in (a) and (b) and organise face-to-face gatherings to increase sharing of knowledge in knowledge sharing systems (VCs).

To validate the research model, a total response of 203 was noted, but only 174 were valid. This provided adequate data, but not a high number for the purposes of running group comparison tests. A higher number of responses may have supported the concepts more strongly. The hypotheses (especially the one relating to innovation orientation and knowledge sharing in VCs), which are not supported by the data could be specific to the sample VCs used. As such, these should be tested on other VCs. 


\section{References}

[1] P. Senge, "Looking ahead: Implications for the present," Harvard Business Review, 1997, 30-32.

[2] F. Reid, "Creating a knowledge sharing culture among diverse business units," Employment Relations Today, 2003, 30 (3): 43-49.

[3] Roger J Calantone, S Tamer Cavusgil and Yushan Zhao, "Learning orientation, firm innovation capability, and firm performance," Industrial Marketing Management, 2002, 515524.

[4] I. Nonaka and H. Takeuchi, The Knowledge-Creating Company: How Japanese Companies Create the Dynamics of Innovation, 1995, NY: Oxford University Press.

[5] C. O’Dell and J. Grayson, Jr., If Only We Knew What We Know, 1998, NY: Free Press.

[6] S. Al-Hawamdeh, Al-Hawamdeh, Knowledge management cultivating knowledge professionals, 2003, Oxford: Chandos Publishing.

[7] M. Jacobson, "Knowledge sharing between individuals" in D G Schwartz (ed) Encyclopedia of Knowledge Management, Hershey, PA: Idea Group Reference, 2006, 507-514.

[8] F. Lin 2007, "The role of online and offline features in sustaining virtual communities: an empirical study," Internet Research, 17 (2): 119-138.

[9] W. Li, "Virtual knowledge sharing in a cross-cultural context," Journal of Knowledge Management, 2010, 14 (1): 38-50.

[10] A. Ardichvili, M. Maurer, W. Li, T. Wentling and R. Stuedemann, "Cultural influences on knowledge sharing through online communities of practice," Journal of Knowledge Management, 2006, 10 (1): 94-107.

[11] S. Bashir, A. Usoro and I. Khan, "Knowledge sharing in virtual communities: Societal culture considerations," International Journal of Economics and Management Engineering, 2014, 1 (1): 12-20.

[12] S Bashir, A. Usoro, A., and Khan, I. 2015. Knowledge sharing in virtual communities: A comparison of three different cultures. Journal of E-Business Development. 5 (1): 12-20.

[13] I. Khan, A. Usoro, G. Majweski and M. Kuofie, "An Organisational Culture Model for Comparative Studies: A Conceptual View," International Journal of Global Business, 2010, 3 (1): 53-82.
[14] A. Usoro, M. Sharratt, E Tsui and S. Shekhar, "Trust as an antecedent to knowledge sharing in virtual communities of practice," Knowledge Management Research and Practice, 2007, 5: 199-112.

[15] Don A. Dillman, D Jolene Smyth and Leah Melani Christian, Internet, Mail, and Mixed-Mode Surveys: The Tailored Design Method. Hoboken, 2009, NJ, John Wiley and Sons.

[16] E. Babbie, Survey Research Methods, 1990, Belmont, California: Wadsworth publishing.

[17] A. Field, Discovering Statistics using SPSS, 2009, Los Angeles: Sage Publication Ltd.

[18] J. Pallant, SPSS Survival Manual: A Step by Step Guide to Data Analysis Using SPSS for Windows, 2010, Berkshire, England: Open University Press.

[19] L. Cohen, L. Manion and K. Morison, 2007. Research Methods in Education, 2007, London: Routledge.

[20] I. Al-Alawi, Y. Al-Marzooqi, Y., and Mohammed, F. 2007. Organisational culture and knowledge sharing: Critical success factors. Journal of Knowledge Management. 11 (2): $22-42$.

[21] Harry Scarbrough, "Knowledge management, HRM and the innovation process," International Journal of Manpower, 2003, 24 (5): 501-516.

[22] Rand Kamasak, F. Bulutlar, "The influence of knowledge sharing on innovation," 2010, European Business Review, 22: 306-317.

[23] D. Dougherty, Managing your core in-competencies for corporate venturing. Entrepreneurship - Theory and Practice, 1995, 19 (3): 113-35.

[24] J. Preece, Online Communities-Designing Usability, Supporting Sociability, 2000, Chichester, NY: John Wiley and Sons.

[25] C. Camison, D. Palacios, F. Garrigos and C. Devece, Connectivity and knowledge management in virtual organisations, 2009, NY: Information Science Reference.

[26] S. Lee, D. Vogel, and M. Limayem, "Virtual community informatics: a review and research agenda," Journal of Information Technology, 2003, Theory and Application. 5 (1): 47-61.

[27] R. Hiebeler, "Benchmarking knowledge management," Strategy and Leadership, 1996, 24 (2): 22-29. 